\title{
Maternal anxiety and its correlation with pain experience during chorion villus sampling and amniocentesis
}

\author{
Katharina Klages ${ }^{1,2}$ \\ Sudip Kundu' \\ Joachim Erlenwein ${ }^{3}$ \\ Michael Elsaesser ${ }^{4}$ \\ Peter Hillemanns' \\ Alexander Scharf ${ }^{4}$ \\ Ismini Staboulidou'
}

'Department of Gynecology and Obstetrics, Hanover Medical School, Hanover, ${ }^{2}$ Department of Gynecology and Obstetrics, Diakovere

Friederikenstift Hanover, Hanover, ${ }^{3}$ Department of Anesthesiology, University of Goettingen, Pain Clinic, Goettingen, ${ }^{4}$ Department of Gynecology and Obstetrics, University of Heidelberg, Heidelberg, Germany
Correspondence: Ismini Staboulidou Department of Gynecology and Obstetrics, Hanover Medical School, Carl-Neuberg-Str. I, 30625 Hannover, Germany

Tel $+49 I 76 I 5323452$

Fax +495115326145

Email staboulidou.ismini@mh-hannover.de
This article was published in the following Dove Press journal:

Journal of Pain Research

13 March 2017

Number of times this article has been viewed

Purpose: Invasive prenatal diagnostic procedures, such as chorion villus sampling (CVS) and amniocentesis (AC), are routinely performed to exclude or diagnose fetal chromosomal abnormalities. The aim of this study was to investigate anxiety-dependent pain experience during CVS and AC and the potential factors that increase anxiety and pain levels.

Patients and methods: During a 2-year period, women undergoing invasive procedures in three specialist centers were asked to participate in the study. Anxiety was evaluated before the procedure using the Spielberger State-Trait-Anxiety-Inventory, and pain was evaluated directly after the procedure using a verbal rating scale.

Results: Among the women, 348/480 (73\%) underwent AC, while 131/480 (27\%) underwent CVS. There was a significant correlation between state and trait anxiety $(p<0.0001)$. A positive correlation existed between the degree of anxiety and the level of pain experienced $(p=0.01)$. There was a positive correlation for trait anxiety $(p=0.0283)$ as well as for state anxiety $(p=0.0001)$ and pain perception ( $p=0.0061)$ when invasive procedure was performed owing to abnormal ultrasound finding or to a history of fetal aneuploidy. Maternal age was found to be another influencing factor for the experienced pain $(p=0.0016)$. Furthermore, the analysis showed a significant negative correlation between maternal age and anxiety. That applies for trait anxiety ( $p=0.0001)$ as well as for state anxiety $(p=0.0001)$. The older the woman, the less anxious the reported feeling was in both groups. The main indication for undergoing CVS was abnormal ultrasound results (45\%), and the main reason for undergoing AC was maternal age (58\%).

Conclusion: Procedure-related pain intensity is highly dependent on the degree of anxiety before the invasive procedure. In addition, the indication has a significant impact on the emerging anxiety and consequential pain experiences. These influencing factors should therefore be considered during counseling and performance.

Keywords: invasive prenatal procedure, chorion villus sampling, amniocentesis, anxiety, procedure-related pain

\section{Introduction}

Invasive prenatal diagnostic procedures, such as chorion villus sampling (CVS) and amniocentesis (AC), are routinely performed to exclude or diagnose fetal chromosomal abnormalities. Intra-amniotic infection and fetal loss are two complications that may occur as a result of prenatal invasive procedures. Recent studies demonstrate that procedure-related miscarriages occur in $<1 \%$ of cases for CVS and AC when performed before 24 weeks of gestation; this rate does not differ from pregnancies in women who have not undergone invasive procedures. ${ }^{1-4}$ Considering the factors that increase fetal loss in general, a review showed that procedure-related risks are $0.2 \%$ and $0.1 \%$ in women who have undergone CVS and AC in specialist centers, respectively. ${ }^{3}$ 
Generally, anxiety prior to undergoing surgery is experienced by $\sim 60 \%-70 \%$ of adult patients. ${ }^{5}$ Pain is described as a subjective experience. No direct relationship between physical pathology and the intensity of pain has been demonstrated so far. This makes it more difficult to objectively quantify pain and also explains why the perception of pain differs between individuals. ${ }^{6} \mathrm{~A}$ high concordance is reported between preoperative levels of anxiety, anticipated pain, and postoperative pain intensity. ${ }^{6,7}$

Various studies have investigated pain experience during prenatal invasive procedures. Results have indicated that CVS and $\mathrm{AC}$ are associated with discomfort, tolerable levels of pain, or are nearly painless. In addition, a positive correlation was demonstrated between women's levels of anxiety and the intensity of their pain experience. ${ }^{8-18}$

The main objective of this study was to investigate the association between anxiety and related pain during CVS and AC by considering anxiety levels. The novelty of this study is the assessment of state and trait anxiety using State-Trait Anxiety Inventory (STAI) questionnaire and the correlation of preexisting trait anxiety and procedure-related state anxiety with pain perception during invasive procedures.
Factors that caused or increased the degree of anxiety were also examined.

\section{Patients and methods Study population}

This prospective observational cohort study took place over a period of 2 years at the Department of Fetal Medicine at the Medical School of Hannover, University of Heidelberg, and at a specialist center of fetal medicine in Braunschweig, Germany. All women undergoing invasive procedures, specifically CVS and AC, were asked to participate in the study. Every woman was informed about the study concept, and the order of study events was explained. After the women agreed to participate, informed consent was obtained from the participants. We questioned the women about their anxiety before the procedure. This was done through the STAI, which was a self-administered questionnaire. Further details of study population and setting are displayed in Figure 1. During the procedures, 19-gauge heparinized needles were used for CVS, and 20-gauge nonheparinized needles were used for AC. All CVS were performed transabdominally, and local anesthetic agent (1\% Lidocaine) was used for every CVS. No local anesthesia was used in AC.

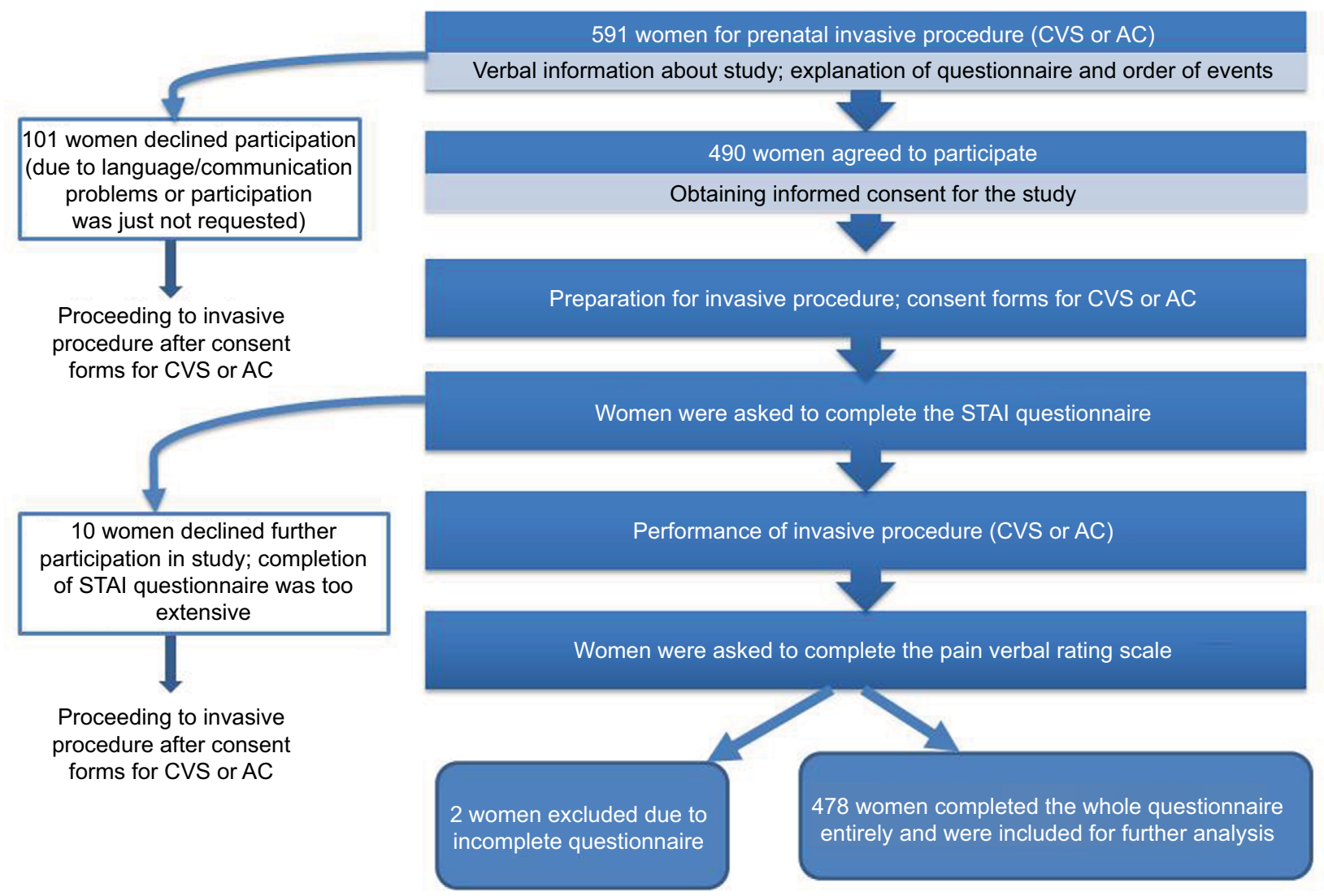

Figure I Study design.

Abbreviations: CVS, chorion villus sampling; AC, amniocentesis; STAI, State-Trait Anxiety Inventory. 


\section{Measurements \\ Anxiety}

The anxiety of the women was assessed using the STAI. The STAI is one of the most widely used scientific questionnaires to assess anxiety. The Laux et a ${ }^{19}$ version, which was used in this study, is based on the original Spielberger (1970) version. Its use has been repeatedly validated and tested in perinatal studies. ${ }^{19-23}$ The STAI questionnaire consists of two independent parts: one is designed to assess state anxiety and the other to assess trait anxiety. To determine state anxiety, the current mood of the person is assessed and their anxiety in a particular moment is measured. To determine trait anxiety, the person's anxiety in general is assessed and their general anxiety is measured. The STAI aims to demonstrate the correlation between anxiety as a state (state anxiety) and anxiety as a trait (trait anxiety) while taking into account the influences of certain life circumstances. ${ }^{19-23}$ The STAI questionnaire contains 20 items intended to register anxiety and stability. The sum of the item values describes the degree and intensity of the anxiety experienced. A value of 20 corresponds with no/minimum anxiety, and a value of 80 corresponds with a marked/maximum anxiety. Based on previous literature and the findings of various international studies, three groups were created for further analysis. A score of 20-40 correlates with no anxiety or nearly no anxiety, a score of 41-60 with moderate anxiety, and a score of $61-80$ with high anxiety. ${ }^{23-27}$

\section{Pain}

The actual pain experienced during sampling was assessed immediately after the procedure. The women were asked to mark their pain experience on a verbal rating scale (no pain, mild pain, moderate pain, strong pain, marked/severe pain, unbearable pain).

\section{Ethical approval}

The study was approved by the local university Ethics Committee of Hanover Medical School. All patients received verbal information about the study before participation and gave informed signed consent.

\section{Statistical analysis}

The statistical analysis was performed in collaboration with the Institute of Statistics of the Leibniz-University of Hanover. Correlation analysis was performed, and the significance of correlations was tested. The corrected contingency coefficient $\left(\mathrm{K}^{*}\right)$ as a measure of the relationship between the variables was calculated for nominal scaled variables. $\chi^{2}$ test was performed to test for any significant correlation.
Spearman's correlation coefficient was performed to measure the relationship of ordinal scaled data.

Logistic regression was adapted to the data if rational and possible. To examine the variables for independency, the correlation was additionally analyzed in a cross-sectional binary data model. Statistical analysis was performed using the statistic program R (https://www.r-project.org). Statistical significance was achieved if $p<0.05$.

\section{Results}

Four hundred and seventy-eight women completely answered the questionnaire and were included in the analysis. In the study population, the mean age was $35.3 \pm 4.6$ years. Of these women, $348(72.7 \%)$ underwent $\mathrm{AC}$ and 131 (27.3\%) underwent CVS. In the CVS and AC groups, the mean maternal age was $34.6 \pm 5.0$ years and $35.6 \pm 4.5$ years, respectively. The mean gestational age was $12.9 \pm 1.4$ weeks in the CVS group and $16.0 \pm 1.6$ weeks in the AC group. There were 54 (41\%) primigravidae in the CVS group and 145 (42\%) primigravidae in the AC group. Ninety-one (70\%) women of the CVS group and 232 (67\%) women of the AC group had no previous miscarriage. One hundred and four (79\%) women of the CVS group and 258 (74\%) of the AC group were married. One hundred and eleven (85\%) and 308 (89\%) women of the CVS and AC groups, respectively, were German, and $6(4.5 \%)$ and $15(4 \%)$ women of the CVS and the $\mathrm{AC}$ groups, respectively, were members of EU countries.

Logistic regression analysis was performed to identify relevant covariates, which could have an influence on anxiety levels and the experienced pain. We analyzed maternal age ( $p=0.036)$, parity $(p=0.93)$, miscarriage $(p=0.56)$, nationality ( $p=0.50)$, occupation $(p=0.92)$, marital status $(p=0.24)$, and indication of invasive procedure $(p=0.0001)$.

Bivariate analysis revealed that the influencing covariates were maternal age and the indication of invasive procedure. The various possible indications for this procedure are shown in Table 1.

The STAI questionnaire was completed by all 348 women who underwent $\mathrm{AC}$ and by 130 of 131 women who underwent CVS. Details of descriptive analysis for state and trait anxiety for the whole study population are displayed in Table 2 . Levels of state and trait anxiety with regard to the CVS and the AC groups are shown in Table 3. The analysis revealed a positive correlation between state and trait anxiety for the whole study population and in both groups, as demonstrated in Figures 2-4 (whole study population $r=0.64854, p<0.0001$; CVS: $r=0.5458, p<0.0001$; AC: $r=0.67015, p<0.0001)$. 
Table I Demographic details

\begin{tabular}{llll}
\hline Characteristics & $\begin{array}{l}\text { Study } \\
\text { population }\end{array}$ & CVS & AC \\
\hline Number of women, N (\%) & 479 & $131(27.3)$ & $348(72.7)$ \\
Maternal age (years); & 35.3 & 34.6 & 35.6 \\
mean (range) & $(20.0-47.0)$ & $(20.0-43.0)$ & $(20.0-47.0)$ \\
Gestational age (weeks); & 15.5 & 12.9 & 16.0 \\
mean (range) & $(I I .0-30.0)$ & $(I I .0-16.0)$ & $(16.0-30.0)$ \\
Primiparous, N (\%) & $199(41.5)$ & $54(41.2)$ & $145(41.7)$ \\
Multiparous, N (\%) & $280(58.5)$ & $77(58.8)$ & $203(58.3)$ \\
Previous abortion, N (\%) & $156(32.6)$ & $40(30.5)$ & $116(33.3)$ \\
\hline
\end{tabular}

Abbreviations: CVS, chorion villus sampling; AC, amniocentesis.

Table 2 Indication for invasive procedure

\begin{tabular}{lll}
\hline Indication & CVS & AC \\
& N=13 I & N=348 \\
\hline Abnormal first trimester screening & $50(38.2)$ & $7 \mid(20.4)$ \\
$>35$ years & $45(34.4)$ & $201(57.8)$ \\
$\begin{array}{l}\text { Previous chromosomal abnormality/previous } \\
\text { aneuploidy }\end{array}$ & $14(10.7)$ & $17(4.9)$ \\
Abnormality during anomaly scan & $9(6.9)$ & $10(2.9)$ \\
Parents' request & $13(9.9)$ & $44(12.6)$ \\
Infection & 0 & $5(1.4)$ \\
\hline
\end{tabular}

Note: Data are presented as N (\%).

Abbreviations: CVS, chorion villus sampling; $A C$, amniocentesis.

Figure 5 displays the pain experience in the whole study population, showing the majority of women having expressed up to mild pain. Regarding the CVS and AC groups, the pain experience seems to be higher in the CVS group. In the CVS group, 114 (87\%) women stated that they experienced no pain up to moderate pain, and 17 (13\%) women stated that they experienced up to marked pain. In the AC group, $325(93.4 \%)$ women reported perceiving no pain or up to moderate pain, and 23 (6.6\%) women reported experiencing up to marked pain.

Comparing the CVS and AC groups, the data showed that women receiving CVS were more anxious (29.9\%) than those receiving AC (18.1\%). Furthermore, $13 \%$ of women in the CVS group experienced up to severe pain compared with $6.6 \%$ of women in the $\mathrm{AC}$ group who experienced severe pain.

Figures 6 and 7 demonstrate that the women felt more pain with increasing state anxiety and trait anxiety, respectively. Furthermore, the analysis showed a significant correlation

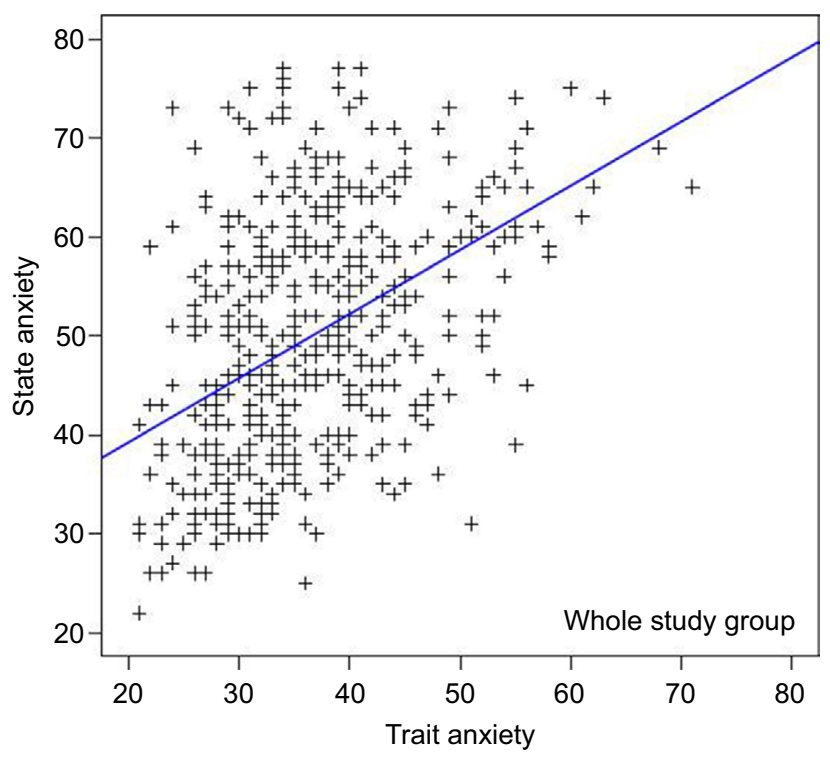

Figure 2 Correlation of state and trait anxiety in the whole study group $(r=0.64854$, $p<0.0001$ ).

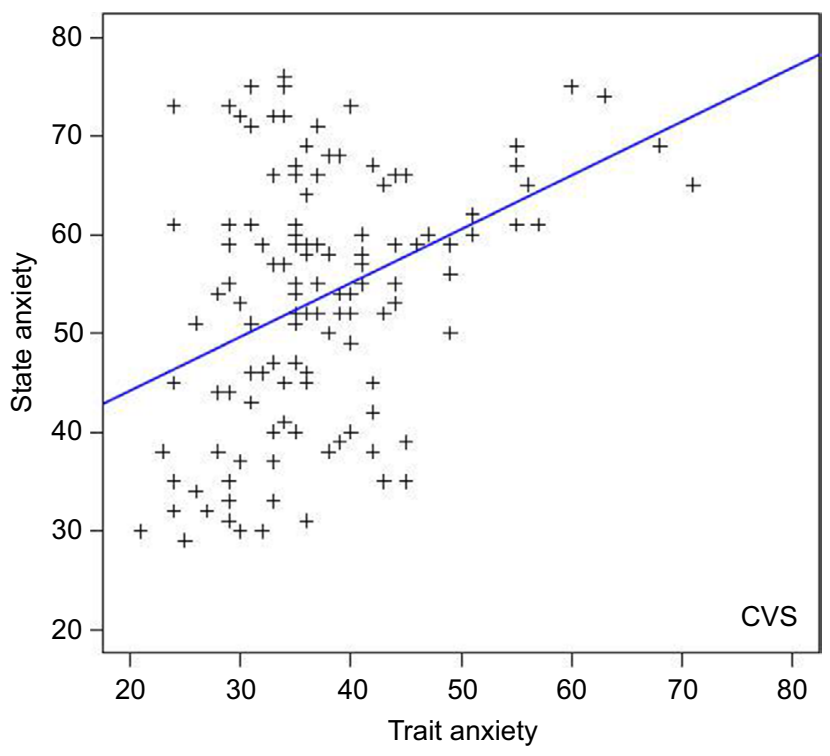

Figure 3 Correlation of state and trait anxiety in the group undergoing CVS $(r=0.5458, p<0.0001)$.

Abbreviation: CVS, chorion villus sampling.

between state anxiety and pain intensity, when regarding the whole study population $\left(\mathrm{r}_{\mathrm{s}}=0.30, p=0.001\right)$, CVS group $\left(\mathrm{r}_{\mathrm{s}}=0.35, p=0.001\right)$, and AC group $\left(\mathrm{r}_{\mathrm{s}}=0.27, p=0.001\right)$, respectively. Except for trait anxiety in the AC group $\left(\mathrm{r}_{\mathrm{s}}=0.08\right.$, $p=0.13$ ), there was also a significant correlation between trait

Table 3 Level of anxiety in comparison: CVS and AC

\begin{tabular}{|c|c|c|c|c|c|c|c|c|c|}
\hline \multicolumn{2}{|c|}{ Level of anxiety } & \multicolumn{4}{|c|}{ CVS $(\mathrm{N}=130)$} & \multicolumn{4}{|c|}{$A C(N=348)$} \\
\hline & & Trait (N) & Trait (\%) & State $(\mathbf{N})$ & State (\%) & Trait (N) & Trait (\%) & State $(\mathbf{N})$ & State (\%) \\
\hline $20-40$ & No or nearly not anxious & 94 & 71.8 & 28 & 21.4 & 264 & 75.9 & 106 & 30.5 \\
\hline $4 \mid-60$ & Moderatelyanxious & 33 & 25.2 & 63 & 48.1 & 82 & 23.6 & 179 & 51.4 \\
\hline $61-80$ & Very anxious & 3 & 2.3 & 39 & 29.9 & 2 & 0.6 & 63 & 18.1 \\
\hline
\end{tabular}

Abbreviations: CVS, chorion villus sampling; AC, amniocentesis. 


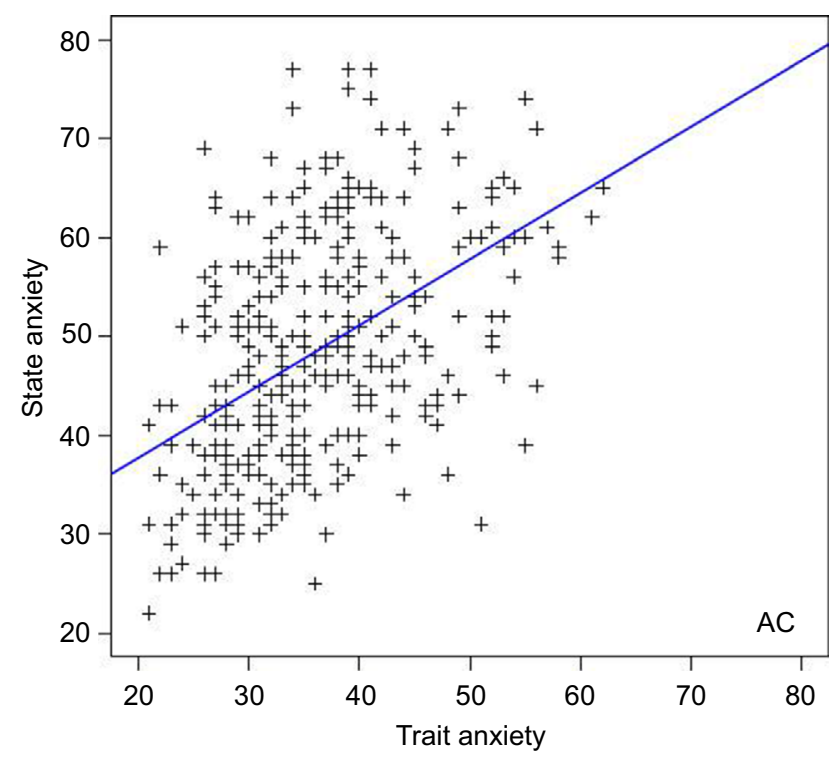

Figure 4 Correlation of state and trait anxiety in the group undergoing amniocentesis $(r=0.67015, p<0.000 \mathrm{I})$.

Abbreviation: AC, amniocentesis.

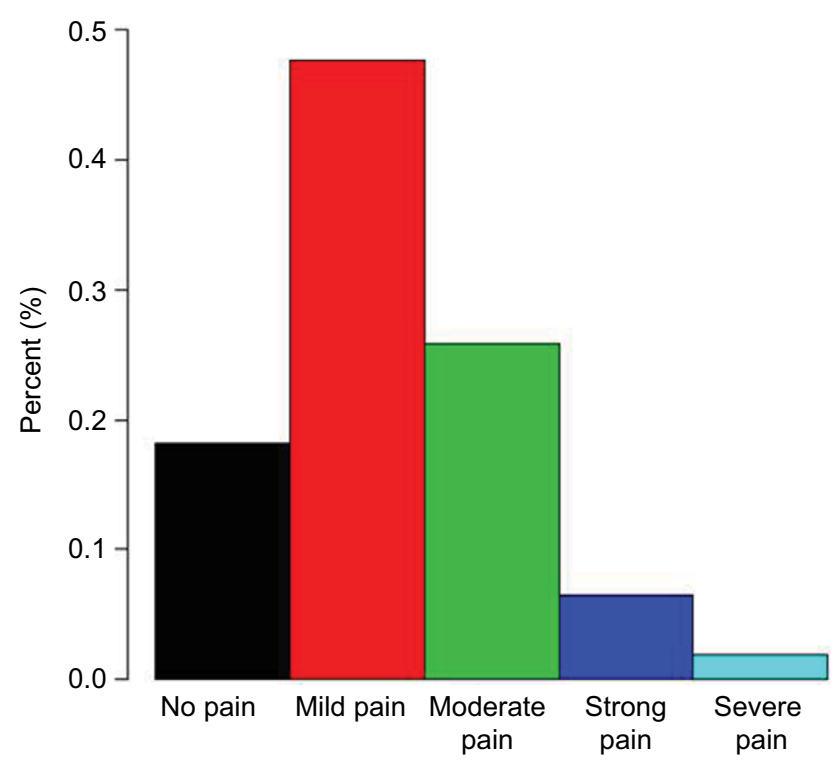

Figure 5 Pain experience in the whole study group.

anxiety and pain intensity in the whole study group $\left(\mathrm{r}_{\mathrm{s}}=0.12\right.$, $p=0.01)$ and in the CVS group $\left(\mathrm{r}_{\mathrm{s}}=0.18, p=0.04\right)$.

The analysis revealed differences in anxiety and pain levels when considering the indication of invasive procedure. There was a significant positive correlation for trait anxiety $(r=1.776, p=0.0283)$ as well as for state anxiety $(r=7.2054$, $p=0.0001$ ) when invasive procedure was performed owing to an abnormal ultrasound finding or a history of previous aneuploidy. The indication for invasive procedure also significantly influenced the pain perception. The women expressed more pain when invasive procedure was performed owing to an abnormal ultrasound finding or a history of previous aneuploidy $\left(\mathrm{K}^{*}=0.2416, p=0.0061\right)$.

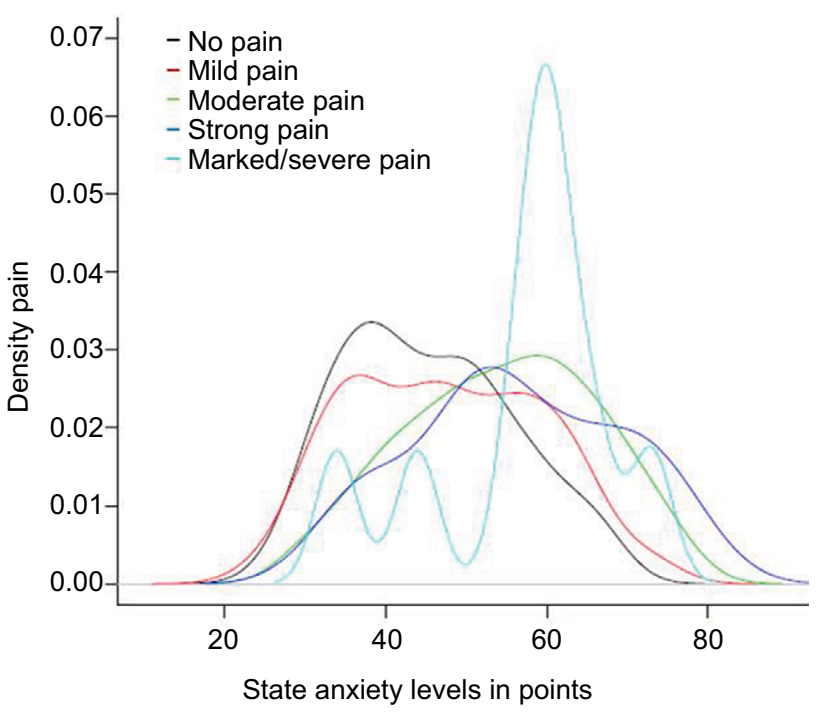

Figure 6 State anxiety and pain experience displayed for the whole study population.

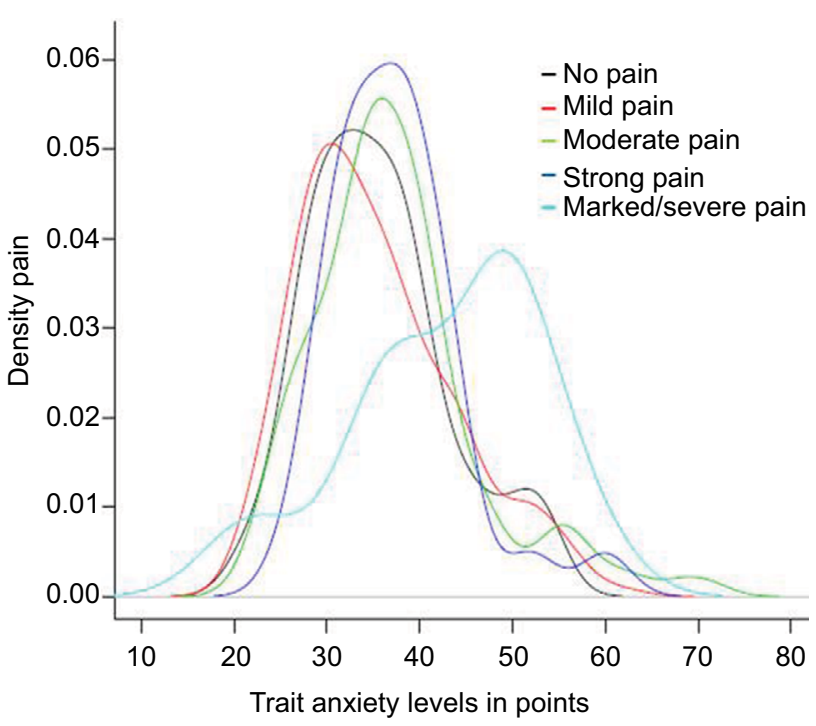

Figure 7 Trait anxiety and pain experience displayed for the whole study population.

Next to the indication for invasive procedure, maternal age was found to be another influencing factor for the experienced pain $\left(\mathrm{K}^{*}=0.2646, p=0.0016\right)$. Furthermore, the analysis showed a significant negative correlation between maternal age and anxiety. That applies for trait anxiety $(r=-3.2567$, $p=0.0001)$ as well as for state anxiety $(r=-6.1881, p=0.0001)$. The older the woman, the less anxious is the reported feeling in both groups.

The levels of anxiety and pain intensity were lowest when the invasive procedure was performed because of maternal age or by request. However, levels of anxiety and pain were greatest when the invasive procedure was performed owing to an abnormal ultrasound finding in the first or second trimester. These results match the aforementioned findings 
that anxiety and pain levels are lower when maternal age is the reason to conduct the invasive procedure. Additional details are provided in Table 4 showing the mean and standard deviation of the state anxiety levels separated for the CVS and AC groups.

The results show that anxiety and pain levels differ regarding maternal age and the indication for invasive procedure. However, maternal age seems to have an impact on the indication for invasive procedure. To analyze whether maternal age influences the indication for invasive procedure and whether the examined variables are independent covariables, a cross-sectional analysis was performed. After performing the cross-sectional analysis, only state anxiety $(p=0.0001)$ and maternal age $(p=0.0001)$ remained independent variables.

Figure 8 displays the pain experience with regard to the indication for invasive procedure and maternal age. The figure very nicely demonstrates the dependency of these two covariates. The pain experience in women aged $>35$ years and in women having an invasive procedure owing to maternal age

Table 4 Level of state anxiety depending on maternal age and indication for invasive procedure

\begin{tabular}{lccc}
\hline & \multicolumn{2}{c}{ State anxiety (mean + standard deviation) } \\
\cline { 2 - 4 } & CVS & AC & p-value \\
\hline Maternal age & & & 0.0001 \\
$\leq 35$ years & $57.67 \pm 11.21$ & $51.98 \pm 11.88$ & \\
$\geq 35$ years & $50.24 \pm 12.71$ & $46.83 \pm 11.48$ & \\
Anomalies in ultrasound scan & & 0.0001 \\
Yes & $50.97 \pm 12.76$ & $46.20 \pm 11.02$ & \\
No & $51.31 \pm 11.91$ & $51.81 \pm 12.29$ & \\
\hline
\end{tabular}

Abbreviations: CVS, chorion villus sampling; AC, amniocentesis.
$>35$ years or on request is very similar. Similarly, the pain experience in women aged $<35$ years and in women having an invasive procedure owing to fetal abnormalities or a previous history of abnormal findings is also equal.

\section{Discussion}

Prenatal invasive procedures like CVS and AC are routinely performed to exclude or diagnose fetal abnormalities. In general, these invasive diagnostic procedures are well tolerated by the patients. Nevertheless, various studies demonstrate that CVS and AC induce anxiety and that women undergoing prenatal invasive procedures often report anxiety and pain. ${ }^{5,8-18}$ Investigations on this matter confirmed that the pain experienced was actually much less than expected. ${ }^{9,10,14,18}$

However, some studies reported CVS to be more painful than AC. ${ }^{8,16,18}$ Next to the procedure itself, a higher intensity of pain was caused by the localization of the puncture, especially at the lateral part of the uterus, and the degree of difficulty in performing the procedure. ${ }^{8,16}$ When performing the invasive procedure in the lower lateral third of the uterus, perceived pain intensity was increased. The authors suggest that this may result from a more concentrated nerve supply to the lower uterus and cervix. ${ }^{8,10,16}$ These aforementioned factors that influence the pain in CVS can also be observed in AC. ${ }^{8-10,12}$ Some studies, comparing all three sampling methods (ie, transabdominal, transcervical CVS and AC), reported that transabdominal CVS was associated with greater pain scores than the other methods. Increased maternal abdominal wall thickness is an important contributing factor to the intensity of the pain experienced. ${ }^{9,10,14}$ Another influencing factor appeared
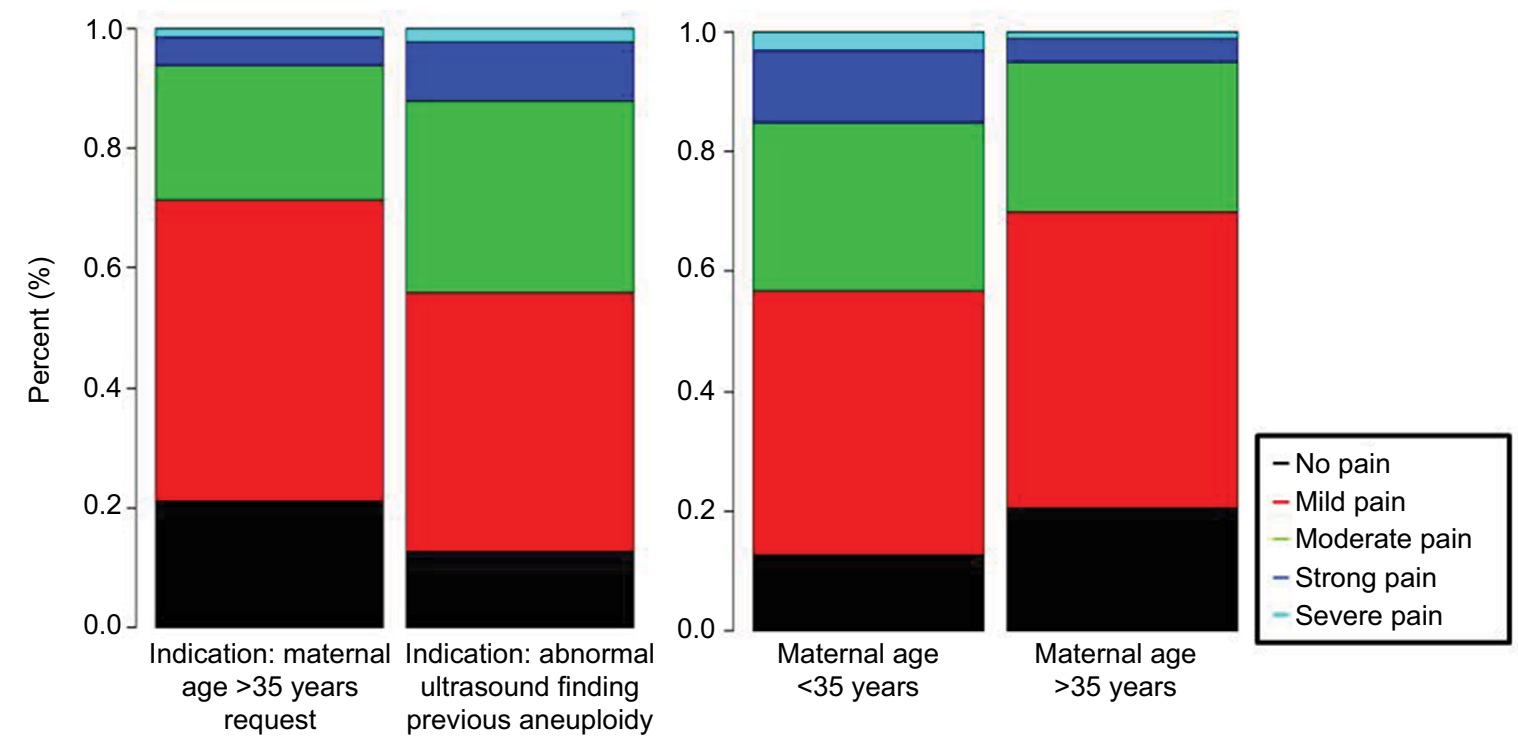

Figure 8 Pain experience depending on influencing factors: indication for invasive procedure $(p=0.006 \mathrm{I})$ and maternal age $(p=0.006 \mathrm{I})$. 
to be the size of the needle. ${ }^{13,14,16}$ Most studies demonstrate that perceived pain was higher when using 18/19-gauge needles instead of 22-gauge needles. These studies conclude that there is no need to perform CVS with 18/19-gauge needles because sampling results are sufficient with 22 -gauge needles. . $^{13,14,16}$

One of the limitations of this study was that we did not document the localization of the puncture, the abdominal wall thickness, and the degree of difficulty when performing the procedure.

Another limitation of this study was that the questionnaire was available only in German. We did not provide a translation in other languages. Therefore, women who had no sufficient German skills declined to participate as they were not able to complete the questionnaire.

Previous studies have demonstrated that providing local anesthesia during AC does not impact individuals' pain levels when compared with the pain intensity of individuals who did not receive local anesthesia. ${ }^{28,29}$ In our study, local anesthetic was not used before AC. However, local anesthetic was used before every CVS. Severe pain was reported by $13 \%$ of the women undergoing CVS and by $7 \%$ of the women undergoing AC. Despite providing the local anesthetic agent, the results of our study showed that the described pain intensity was higher in the CVS group than in the AC group. This is compatible with the results of previous studies ${ }^{28,29}$ that showed no benefit in using local anesthetics before AC, as pain intensity was not decreased in women receiving local anesthesia. These findings suggest that psychological influences have more of an impact on pain perception than the actual physical sensations experienced during these invasive procedures. This estimation is confirmed by the fact that women's reasons for having these procedures impacted their pain perceptions.

Data from the literature ${ }^{8-18}$ and from this study demonstrate that prenatal diagnosis may induce concerns about a potential abnormal result. Women undergoing CVS experienced more stress and anxiety than women undergoing AC. Levels of stress were also increased based on indication for invasive procedure and information about the anticipated pain. Although the results of this study demonstrated that women in both groups were anxious, the mean state anxiety level was higher in the CVS group (53.5) than in the AC group (48.3). As shown in Table 3, women in the CVS group reported moderate or high levels of state anxiety more often than women in the AC group. Our results also showed a positive correlation between anxiety levels and perceived pain intensity. The strongest declarations of pain were found in the group with higher levels of state anxiety and in the women who underwent both CVS and AC.
These findings confirm previous results. ${ }^{8-10,13}$ Comparing transabdominal and transcervical CVS and $\mathrm{AC}$, the expected pain was much higher than the experienced pain independent of the sampling method. Anxiety was once again an important contributing factor to the perceived pain. ${ }^{13}$

In addition, the results of this study demonstrated a significant correlation between trait anxiety and state anxiety. Trait anxiety shows how dispositionally anxious a person is across time and situation, whereas state anxiety indicates how anxious a person is feeling at a particular moment and is influenced by fear, tension, nervousness, and the situation itself. Trait anxiety influences an individual's assessment of a situation, as either threatening or not threatening, and increases their state of anxiety accordingly. This was demonstrated in our results. Women with higher levels of trait anxiety also reported higher levels of state anxiety.

Previous studies revealed that emotional variation exists during pregnancy and that pregnant women have increased levels of anxiety. ${ }^{27}$ Maternal anxiety originates in fears that are related to fetal well-being, good pregnancy outcomes, and one's own health condition. Therefore, it is comprehensible that anxiety levels vary during pregnancy, depending on gestational age and the presence of pregnancy-related complications. Regarding trait anxiety scores in the CVS and AC groups, they are very similar and there are no significant differences. The trait scores of this study are concordant with the results of other studies that sought to measure the degree of anxiety in pregnant women. The results of those studies demonstrated that pregnant women have higher levels of trait anxiety than nonpregnant women. ${ }^{19,23,27,30-34}$

Different degrees of state and trait anxiety may occur during pregnancy. Maternal anxiety peaks in the first and third trimesters, with the highest score in the third trimester. A similar course has also been described for trait anxiety because researchers have identified a positive correlation with gestational age..$^{27,30-34}$ These data confirm that emotional state/mood during pregnancy can be modified by different factors that influence anxiety levels. The results suggest that anxiety and pain perception are significantly impacted by the indication for invasive testing.

Overall, these data show that during pregnancy, anxiety as an emotion can vary in special situations, as can disposition. Therefore, pregnancy appears to be a special emotional condition. The correlation of trait anxiety and state anxiety therefore seems to be logical, as the factors influencing the emotional well-being of pregnant women are multifactorial. When pregnant women experience anxiety prior to invasive prenatal procedures, the anxiety is predominantly related 
to fear of an abnormal result rather than fear of pain. This estimation is underlined by previous studies that revealed that state anxiety is much higher in pregnant women who are facing an invasive procedure or fetal therapy procedure. The primary cause for concern was worry about the fetus and not about the anticipated pain. ${ }^{35,36}$

It seems obvious that a variety of factors can impact the degree of anxiety experienced and the associated pain experienced. In particular, the indication for the procedure has a significant impact on anxiety levels and perceived pain, as already mentioned. When CVS or AC is performed owing to fetal abnormalities, it causes higher levels of anxiety and pain. Regarding CVS, anxiety levels and experienced pain intensities were reportedly higher. Considering the indication for CVS or AC, 55.7\% of women underwent CVS because they had abnormal findings during their scans or had a history of previous chromosomal or structural anomalies, while only $28.1 \%$ of women underwent AC for those reasons. These results suggest that the main reason for a higher intensity of pain during CVS is mainly a higher level of anxiety in those women, rather than the pain related to CVS as a procedure. Preprocedural anxiety also impacts women by increasing their pain levels during the procedure. Our results are concordant with those of previous studies ${ }^{8-10,13,14,16}$ that show certain factors influencing and possibly increasing anxiety levels: maternal age, nulliparity, the woman's reasons for an invasive procedure, and a history of invasive procedures in previous pregnancies. Our data indicated that a negative correlation exists with maternal age: in both groups, levels of anxiety and pain decreased as the maternal ages increased. Furthermore, the analysis showed that maternal age has an impact on the indication for invasive procedures. These results align with women's reasons for an invasive prenatal procedure. In 57.8\% of the women, $\mathrm{AC}$ was performed because maternal age was $>35$ years, and in $34.4 \%$ of the women CVS was performed because maternal age was $>35$ years. Pregnant women with high-risk screening results or abnormal ultrasound findings may experience greater anxiety and associated pain than women who choose to have an invasive diagnostic test purely on the basis of advanced maternal age.

A previous study demonstrated an underestimation of women's stress by the doctor. ${ }^{16}$ The results from our study and previous studies demonstrate that anxiety can influence the perception of pain during CVS as well as AC. Therefore, it is both advisable and necessary to consider the reasons why pregnant women are undergoing invasive procedures. This will allow practitioners to be more supportive and reassuring during both counseling and the procedure itself. The intention is to decrease anxiety in pregnant women before the procedure and to reduce the perceived pain during the procedure. Additional information and adequate counseling seems to decrease maternal worries and anxiety most of the time. 9,37,38 Increasing pregnant women's knowledge of prenatal examinations is demonstrated to increase these women's sense of well-being and to significantly decrease their anxiety and worry. ${ }^{10}$ The ultrasound examination and counseling by a qualified physician can have a positive emotional impact on the psyche of pregnant women. ${ }^{38-40}$ This counseling should include discussing the risks involved in invasive procedures because this is a major concern of women who opt for invasive testing. Most women accept the discomfort or even the perceived pain because they want to gain reassurance or a clear diagnosis. ${ }^{15}$

It is therefore very important that pregnant women are provided with accurate estimates of the risks associated with invasive procedures. As researchers update procedure-related risk estimation, physicians should incorporate the new data when counseling women, thereby allowing them to make appropriate choices. With adequate counseling, it should be possible to prevent such increases in anxiety levels in pregnant women and their subsequent perceptions of pain.

Data from the literature and from this study indicate that counseling and final decisions about performing either CVS or AC should be based primarily on gestational age, indication for invasive testing, physicians' expertise, placental localization, accessibility of the procedures, and patient choice, as both procedures are generally well tolerated.

\section{Conclusion}

The results from this study emphasized the importance of providing good counseling for planned invasive procedures. In addition, they emphasized the importance of the indication for the invasive testing or the women's previous medical history and anxiety levels.

Current anxiety levels are altered by present individual anxiety levels that characterize each person. Anxiety levels in turn influence the perception of pain. The results of this study indicate that the more anxious the patient, the higher her perceived pain intensity will be. A balance should be achieved between providing adequate information to enable women to make informed choices and not causing increased worry or anxiety among parents and pregnant women. Reducing women's anxiety and stress might reduce the procedure-related pain.

\section{Acknowledgments}

We would like to thank Dr Schuette and the Fetal Medicine Center in Braunschweig, Germany, for taking part in this 
study. Furthermore, we would like to thank Prof Sibbertsen and Dr Betram, Institute of Statistics, of the Leibniz-University of Hanover, for the statistical analysis.

\section{Author contributions}

All authors contributed toward data collection and interpretation, drafting and critically revising the paper, and agree to be accountable for all aspects of the work.

\section{Disclosure}

The authors report no conflicts of interest in this work.

\section{References}

1. Akolekar R, Bower S, Flack N, Bilardo CM, Nicolaides KH. Prediction of miscarriage and stillbirth at 11-13 weeks and contribution of chorionic villus sampling. Prenat Diagn. 2011;31:38-45.

2. Wulff CB, Gerds TA, Rode L, Ekelund CK, Petersen OB, Tabor A. Risk of fetal loss associated with invasive testing following combined first-trimester screening for Down syndrome: a national cohort of 147987 singleton pregnancies. Ultrasound Obstet Gynecol. 2016; 47:38-44.

3. Akolekar R, Beta J, Picciarelli G, Ogilvie G, D’Antonio F. Procedurerelated risk of miscarriage following amniocentesis and chorionic villus sampling: a systematic review and metaanalysis. Ultrasound Obstet Gynecol. 2015;45:16-26.

4. Tabor A, Alfirevic Z. Update on procedure related risks for fetal prenatal diagnosis techniques. Fet Diagn Therap. 2010;27:1-7.

5. Ramsay MA. A survey of pre-operative fear. Anaesthesia. 1972;27: 396-402.

6. Turk DC, Okifuji A. Psychological factors in chronic pain. Evolution and revolution. J Consult Clin Psychol. 2002;70:678-690.

7. Logan DE, Rose JB. Is postoperative pain a self-fulfilling prophecy? Expectancy effects on postoperative pain and patient-controlled analgesia use among adolescent surgical patients. J Ped Psych. 2005; 30:187-196.

8. Csaba A, Bush MC, Saphier C. How painful are amniocentesis and chorionic villus sampling? Prenat Diagn. 2006;26:35-38.

9. Ferber A, Onyeije CI, Zelop CM, O'Reilly-Green C, Divon MY. Maternal pain and anxiety in genetic amniocentesis: expectation versus reality. Ultrasound Obstet Gynecol. 2002;19:13-17.

10. Harris A, Monga M, Wicklund CA, et al. Clinical correlates of pain with amniocentesis. Am J Obstet Gynecol. 2004;191:542-545.

11. Karasahin E, Gungor S, Goktolga U, Keskin U, Gezginc K, Baser I. Anticipated and perceived pain from midtrimester amniocentesis. Int J Gynaecol Obstet. 2008;101:290-294.

12. Lekskul N, Tannirandorn Y. The location of needle insertion effect on maternal pain in amniocentesis. J Med Assoc Thai. 2006;89:S137-S141.

13. Vandenbossche F, Horovitz J, Guyon F, Verret C, Saura R. Pain experience during chorionic villus sampling and amniocentesis: a preliminary study. Eur J Obstet Gynecol Reprod Biol. 2008;136:189-193.

14. Wax JR, Davies NP, Watson WJ, et al. Pain associated with chorionic villus sampling: transabdominal vs transcervical approach. Am JObstet Gynecol. 2009;201:400.e1-e3.

15. Locock L, Field K, McPherson A, Boyd PA. Women's accounts of the physical sensation of chorionic villus sampling and amniocentesis: expectations and experience. Midwifery. 2010;26:64-75.

16. Bot-Robin V, Sendon S, Bourzofi K, et al. Maternal anxiety and pain during prenatal diagnostic techniques: a prospective study. Prenatal Diagn. 2012;32:562-568.

17. Sendon S, Salleron J, Bourzoufi K, Dutoit P, Vaast P, Houfflin-Debrarge $\mathrm{V}$. Assessment of anxiety, pain and its management in prenatal diagnosis procedure. J Gynecol Obstet Biol Reprod. 2011;40:246-254.
18. Dadhwal V, Sharma AK, Singh A, Deka D, Mittal S, Kumar G. Clinical correlates of pain and anxiety in prenatal diagnostic procedures. Fet Diagn Ther. 2012;32:190-193.

19. Laux L, Glanzmann P, Schaffner P, Spielberger CD. Das State-TraitAngstinventar (Testmappe mit Handanweisung, Fragebogen STAI-G 63 Form X 1 und Fragebogen STAI-G Form X 2). Göttingen: Beltz Test $\mathrm{GmbH} ; 1981$.

20. Bernstein GA, Garfinkel BD. The visual analogue scale for anxiety revised: psychometric properties. J Anxiety Disorders. 1993;6:223-239.

21. Kindler CH, Harms C, Amsler F, Ihde-Scholl T, Scheidegger D. The visual analog scale allows effective measurement of preoperative anxiety and detection of patients' anesthetic concerns. Anesth Analg. 2000;90:706-712.

22. Meades R, Ayers S. Anxiety measures validated in perinatal populations: a systematic review. J Affect Disord. 2011;133:1-15.

23. Spielberger CD, Gorsuch RL, Lushene RE. Manual of the State-TraitAnxiety Inventory. Palo Alto, CA: Consulting Psychologists Press; 1970.

24. Asplin N, Wessel H, Marions L, Georgsson Öhman S. Maternal emotional wellbeing over time and attachment to the fetus when a malformation is detected. Sex Reprod Healthc. 2015;6:191-195.

25. Tendais I, Costa R, Conde A, Figueiredo B. Screening for depression and anxiety disorders from pregnancy to postpartum with the EPDS and STAI. Span J Psychol. 2014;17:E7.

26. Udry-Jørgensen L, Darwiche J, Germond M, Wunder D, Vial Y. Anxiety, depression, and attachment before and after the first-trimester screening for Down syndrome: comparing couples who undergo ART with those who conceive spontaneously. Prenat Diagn. 2015;35:1287-1293.

27. Newham JJ, Westwood M, Aplin JD, Wittkowski A. State-trait anxiety inventory (STAI) scores during pregnancy following intervention with complementary therapies. J Affect Disord. 2012;142:22-30.

28. Van Schoubroeck D, Verhaege J. Does local anaesthesia at mid-trimester amniocentesis decrease pain experience? A randomized trial in 220 patients. Ultrasound Obstet Gynecol. 2000;16:536-538.

29. Gordon MC, Ventura-Braswell A, Higby K, Ward JA. Does local anaesthesia decrease pain perception in women undergoing amniocentesis? Am J Obstet Gyn. 2007;196(1):55.e1-e4.

30. Haddad PF, Morris NF, Spielberger CD. Anxiety in pregnancy and its relation to use of oxytocin and analgesia during labour. $J$ Obstet Gynecol. 1985;6:77-81.

31. Bhagwanani SG, Seagraves K, Dierker LJ, Lax M. Relationship between prenatal anxiety and perinatal outcome in nulliparous women: a prospective study. J Nat Med Assoc. 1997;89:93-98.

32. Da Costa D, Larouche J, Dritsa M, Brender W. Variations in stress levels over the course of pregnancy: factors associated with elevated hassles, state anxiety and pregnancy-specific stress. J Psychosom Res. 1999;47:609-621.

33. Teixeira C, Figueiredo B, Conde A, Pacheco A, Costa R. Anxiety and depression during pregnancy in women and men. J Affect Disord. 2009;119:142-148.

34. Gunning MD, Denison FC, Stockley CJ, Ho SP, Sandhu HK, Reynolds $\mathrm{RM}$. Assessing maternal anxiety in pregnancy with the state-trait anxiety inventory (STAI): issues of validity, location and participation. J Reprod Infant Psych. 2010;28:266-273.

35. Beck V, Opdekamp S, Enzelin P, et al. Psychosocial aspects of invasive fetal therapy as compared to prenatal diagnosis and risk assessment. Prenat Diagn. 2013;33:334-340.

36. Melville JL, Gavin A, Guo Y, Fan MY, Katon WJ. Depressive disorders during pregnancy: prevalence and risk factors in a large urban sample. Obstet Gynecol. 2010;116:1064-1070.

37. Björklund U, Marsk A, Öhman SG. Dies an information film about prenatal testing in early pregnancy affect women's anxiety and worries? J Psychosom Obstet Gynaecol. 2013;34:9-14.

38. Salmoukas C, Kundu S, Soergel P, Hillemanns P, von Kaisenberg C, Staboulidou I. Background knowledge and attitude of pregnant women towards ultrasound screening at 20-23 weeks gestation. Z Geburtshilfe Neonatol. 2016;220:16-20. 
39. Schoonen HM, Essink-Bot ML, Van Agt HM, Wildschut HI, Steegers EA, De Koning HJ. Informed decision-making about the fetal anomaly scan: what knowledge is relevant? Ultrasound Obstet Gynecol. 2011;37:649-657.
40. Dahl K, Hvidman L, Jorgensen FS, Kesmodel US. Knowledge of prenatal screening and psychological management of test decisions. Ultrasound Obstet Gynecol. 2011;38:152-157.

\section{Publish your work in this journal}

The Journal of Pain Research is an international, peer reviewed, open access, online journal that welcomes laboratory and clinical findings in the fields of pain research and the prevention and management of pain. Original research, reviews, symposium reports, hypothesis formation and commentaries are all considered for publication.
The manuscript management system is completely online and includes a very quick and fair peer-review system, which is all easy to use. Visit http://www.dovepress.com/testimonials.php to read real quotes from published authors. 